\title{
Vaught's Conjecture Workshop Participants
}

\begin{tabular}{|c|c|c|}
\hline & Name & Affiliation \\
\hline 1 & Nate Ackerman & Massachusetts Institute of Technology \\
\hline 2 & Logan Axon & University of Notre Dame \\
\hline 3 & Andrey Babichev & Wesleyan University \\
\hline 4 & Bektur Baizhanov & $\begin{array}{l}\text { University of Illinois at Chicago, } \\
\text { IPIC (Kazakhas) }\end{array}$ \\
\hline 5 & John Baldwin & University of Illinois at Chicago \\
\hline 6 & Timothy Bays & University of Notre Dame \\
\hline 7 & Howard Becker & \\
\hline 8 & Prerna Bihani & University of Notre Dame \\
\hline 9 & John Bourke & Dartmouth College \\
\hline 10 & Steven Buechler & University of Notre Dame \\
\hline 11 & Wesley Calvert & University of Notre Dame \\
\hline 12 & Alice Chan & MIT \\
\hline 13 & John Chisholm & Western Illinois University \\
\hline 14 & Peter Cholak & University of Notre Dame \\
\hline 15 & Joshua Cole & University of Notre Dame \\
\hline 16 & Chris Conidis & The University of Chicago \\
\hline 17 & Alfred Dolich & McMaster University \\
\hline 18 & Damir Dzhalil Dzhafarov & The University of Chicago \\
\hline 19 & Clifton Ealy & University of Illinois-Urbana Champaign \\
\hline 20 & Pantelis Eleftheriou & University of Notre Dame \\
\hline 21 & Rachel Epstein & The University of Chicago \\
\hline 22 & Johanna Franklin & University of California, Berkeley \\
\hline 23 & $\mathrm{Su}$ Gao & University of North Texas \\
\hline 24 & Peter Glenn & Carnegie Mellon University \\
\hline 25 & Christina Goddard & MIT \\
\hline 26 & Noam Greenberg & University of Notre Dame \\
\hline 27 & Valentina Harizanov & George Washington University \\
\hline 28 & Jacob Heidenreich & University of Notre Dame \\
\hline 29 & Greg Hjorth & University of California-Los Angeles \\
\hline 30 & Alekos Kechris & Caltech \\
\hline 31 & Robin Knight & University of Oxford \\
\hline 32 & Julia Knight & University of Notre Dame \\
\hline 33 & Martin Koerwien & Universitè de Paris 7 \\
\hline 34 & Alexei Kolesnikov & University of Michigan \\
\hline 35 & Karen Lange & The University of Chicago \\
\hline 36 & Chris Laskowski & University of Maryland \\
\hline 37 & David Lippel & University of Notre Dame \\
\hline 38 & Yun Lu & Wesleyan University \\
\hline 39 & Chrissy Maher & University of Notre Dame \\
\hline 40 & Dave Marker & University of Illinois at Chicago \\
\hline
\end{tabular}




\begin{tabular}{lll}
\hline \hline & Name & Affiliation \\
\hline \hline & & \\
41 & Charles McCoy & University of Notre Dame \\
42 & Russell Miller & Queens College-CUNY \\
43 & Sara Miller & University of Notre Dame \\
44 & Michael Morley & Cornell University \\
45 & Ludomir Newelski & Wrocław University \\
46 & Christopher Porter & University of Notre Dame \\
47 & Gerald Sacks & Harvard University \\
48 & Davender Sahota & University of Illinois at Chicago \\
49 & Dana Scott & Carnegie Mellon University \\
50 & Ziv Shami & Tel Aviv University \\
51 & Richard Shore & Cornell University \\
52 & Robert Soare & The University of Chicago \\
53 & Slawomir Solecki & University of Illinois-Urbana-Champaign \\
54 & Reed Solomon & University of Connecticut \\
55 & Sergei Starchenko & University of Notre Dame \\
56 & Michael Stob & Calvin College \\
57 & Kathryn Vozoris & University of Illinois at Chicago \\
58 & Jessica Young & University of British Columbia \\
&
\end{tabular}

